\title{
A Preliminary Study on the Application of Statistical Process Control (SPC) Towards Process Efficiency: Case Study in Food Industries
}

\author{
Mohd Fadil Mohd Yunus*, Che Azlan Taib, Rosman Iteng \\ School of Technology Management and Logistics (STML), Universiti Utara Malaysia, 06010 UUM Sintok, Kedah, Malaysia \\ *Corresponding author: mohd_fadil@oyagsb.uum.edu.my
}

\begin{abstract}
Today's in an environment that is becoming increasingly global and challenging, the small and medium entrepreneurs (SMEs) in Malaysia face new challenges with competitive, especially for strengthening the capacity and capability to enhance the performance of processing and production of highquality products. This goal is one of the contribution through the use of a such quality tools likes statistical process control (SPC). SPC is a management tool techniques to control and improve processes in the production industry, but studies on the use of the SPC by the food industry in Malaysia is limited. The use of SPC such as control charts and analysis of process capability ( $\mathrm{Cp}$ ) enable food manufacturers to make decisions and improve quality of products produced to product defect, improve processes, ensure the reliability of the products and thus increase customer satisfaction. A survey was developed based on preliminary study for application of the SPC in the food industry involving in SMEs companies. A total of 30 journal articles are selected for review the scenario implementation of SPC. The articles publishing on the implementation of the SPC in Malaysia focusing on non-food industry such as automotive, health services, textile, semiconductor, construction, chemical and others. A preliminary study show the implementation of the SPC in the food industry is relevant mainly for quality improvement of food safety and enhance opportunity for security for food industry in Malaysia in the future by open global market.
\end{abstract}

Keywords: Preliminary study, Statistical process control (SPC), Food industries

(C) 2016 Penerbit UTM Press. All rights reserved

\subsection{INTRODUCTION}

Quality is an issue that is most important because it is a concept of truth in life. Quality is considered to be weapons in the strategic organization. They are dependent on the development of an organization for upgrading services and quality entails. Quality also has many described in the varied literature. Quality properties that involve customer service and features of a product or service shall be the customer's expectations and lead to customer satisfaction (Juran \& Godfrey, 1999) . Compliance with ISO 9000:2000 stressed that quality is defined as the degree to which a set of features that exist and meet the requirements. The term of quality is very synonymous with our daily lives. Referring to the fourth edition of the Dewan Bahasa dan Pustaka quality refers to the degree of excellence, quality and nature of excellence where excellence itself can be considered as a level increases to a higher level based on the several corners such as the increase in quality and productivity as well as development of a continuous change (Baharom, 2011). Performance to the degree of excellence, quality and also excellence to each organization and industry shall have the competitive factors such as the quality, good marketing, extensive business network, efficient and customer friendly.

Deming is an expert in the field of quality and productivity stated quality as a predictable rate of similarity and manoeuvrability of hope at low cost and in accordance with market needs. He pointed out that quality is a means to meet supply and demand towards customer needs on an ongoing basis. Therefore, fourteen (14) article as spelt out by Deming is important to management for the purpose of improvement in productivity to be implemented (Thareja, Sharma \& Mahapatra, 2011). Juran was formed ten (10) tips to achieve continual quality improvement in an organization. Among the tips covering the technical aspects of quality control to address weaknesses and problems in the organization. View Juran, at least $20 \%$ of the problem of quality is attributable to employees and the rest is due to the management. Therefore, the tip 14 to improve weaknesses in organization and communication between employees and management (Juran \& Godfrey, 1999). Very quality experts known for introducing the concept of ' zero defect ' or zero defect was Philip Bayard Crosby. Philip Bayard Crosby to define quality as consistency with requirements through inspections, testing and revision. Crosby of the opinion firmly against the management's responsibility over quality and promote quality conscious organization similar to expected profits.

As a conclusion, quality refers to the extent to which processes, products, services and relationships are free from defects,constraints and items which do not add value for the customer. Directly or indirectly, the quality of the products much influenced by some of the things preparation materials starting from the reception of raw materials up to the packaging process. Quality in the food industry can be interpreted as a result of the products and services that are in good condition, secure, durable and free from the risk of danger. To produce quality, control should be implemented in advance. 
Quality Management Aspect

Three aspects of quality management can be stated as quality control, quality assurance and quality planning. Quality management also relate to each other between control, assurance and quality enhancement task. A quality management is an organizational culture that have been clearly outlined by supporting the achievement of customer satisfaction through a system that integrates tools, technique and also training. It directly to increase continuously organization processes and produce high quality productivity (Thareja, Sharma \& Mahapatra, 2011).

Quality control (QC) refers to activities to ensure that goods are produced to meet the possibility of the highest quality. Most of the tools and techniques to control quality are with the use of statistical techniques. Quality control techniques are classified into basic, intermediate and advanced levels. Between the basic method was statistically process control (Tybor, Hurst, Reynolds, \& Schuler, 2010). Most countries, food safety and quality become a case of serious doubts. The purpose of this quality control is established to food operators in the awareness to recognize basic principles guarantee satisfactory quality, also on factor demand consumer and food safety. The purpose of quality control is intended (Tybor et al., 2010).

a) Protect customers from the form of the dangers such as contaminated food, and ensure that the goods purchased are of high quality and in accordance with the actual weight in accordance with the amount paid

b) Protect from any form of fraud by suppliers and damage to equipment taken from claimed by middlemen, customers or suppliers.

c) Ensure that the operation of the food laws in the country were observed

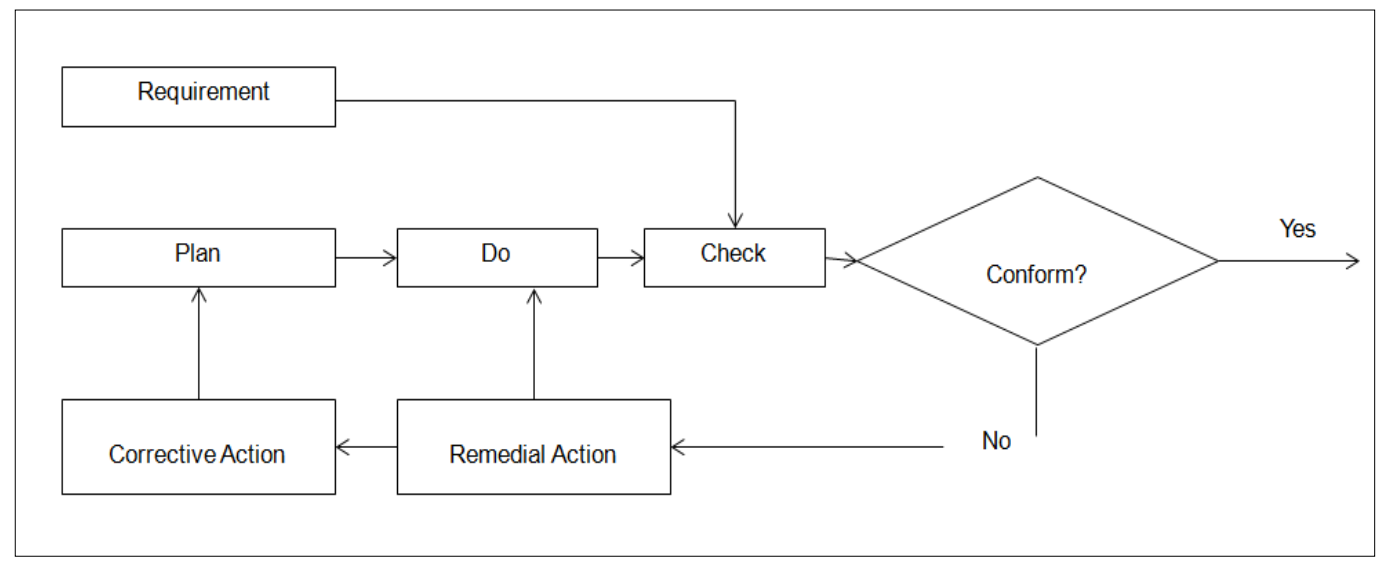

Source: Topic of quality control, www.transition-support.com

Figure 1 A simplest flow quality control process

Figure above shows a simplest flow of quality control process called also as the Cycle Plan-Do-check-Act (PDCA Cycle). PDCA Cycle is a process of effective quality using 4 steps to ensure output meets specified quality standards. Quality control is used as the process of examination of products issued in order to reduce production costs as a result of product damage during the production process, ensuring that each customer get satisfaction on the quality of products and also ensures the company's image is not affected by the failure to safeguard product quality (Popp, Chiou \& Heinemann, 2012). Effective quality control will result in high productivity, reduce production costs and defects of goods and ensure that the number of abandoned goods decreased. Seven tools of quality control (QC) such as pareto chart, graph, scatter diagrams, check sheet, cause and effect diagram, histogram and control chart.

Quality assurance is planned and systematic activities implemented in a quality system. The result is that quality requirement for a product or service will be fulfilled. It is a systematic measurement, comparison with a standard, monitoring of processes and associated with feedback loop that confers error prevention. Quality assurance is a promise by a product or service provider to its customers and includes the management of the quality of raw materials, assemblies, products and components, services related to production and management, and production and implementation process. The are many quality assurance standards used by manufacturing, engineering, production and marketing companies such as ISO 9001, Good manufacturing Practices (GMP), Hazard Analysis Critical Control Point (HACCP) and accreditation of HALAL certification. These quality standards are the international standards that identifies whether a product or service offered meets the specified requirements. Quality assurance system increase customer confidence and company's credibility improves work processes and efficiency and enables a company to better compete with others.

The Malaysian Government is committed to ensuring food safety and quality for the export and domestic market are delivered to. Compliance with the HACCP system used for this purpose where HACCP Scheme was established by giving official recognition to the industry in the field of food implemented since 1996 to fulfil the conditions and criteria for exporting products to the European Union (EU) and certification in U.S.A (Abdullah \& Rosli, 2015). Compliance with HACCP for food processed and controlled by the Ministry of Health (MOH) while HACCP is to raw materials and controlled by the Ministry of Agriculture and Agro-Based Industry (MOA Inc.). Food processing in small and medium enterprises worldwide increasingly thriving and considered the production of quality products as good as needs to their survival. Users and buyers today are more aware of the importance of high-quality product and safe for consumption. In order to improve product quality and productivity, control is the most important aspect of determining the criteria quality required users in any one product is produced. To fulfil these standards, manufacturer should take a serious attitude in controlling the quality system to ensure that product requirements have been routinely meet the criteria. 


\subsection{SIGNIFICANT OF THE STUDY}

This study will be a significant effort in providing a logistic descriptive information about the previous study about SPC tools like capability index, histogram, model DMAIC, control chart, etc. By applying SPC, organizations can achieve continuous quality improvement and maintaining quality products as well as ensuring food quality from start to finished product. The advantages of those tools is that they can identify the effects of the processes that cause unnatural variability in processes that result of errors and poor quality. This study will also be beneficial to the food industry in strategic management and production planning product when they are taking effective action in managing and implementing quality control to improve the company's performance. In addition, this research will provide recommendations on how to improve the performance of process efficiency based on statistical process control to the management of the organisation.

\subsection{LITERATURE REVIEW}

The SPC techniques used are intended to control the process and reduce the variation control and manage a management, a process either in the context of manufactured or services through the process, which is key aspect of improving quality and productivity (Hubbard, 2012). SPC is a tool that will distinguish between cause-specific and common to the variation and it will be used to keep the management process that is not normal. SPC should be adopted voluntarily by management because it requires a high level of motivation and not merely meet the requirements and customer satisfaction alone (Phyanthamilkumaran \& Fernando, 2015).

\section{Concept of Statistical Process Control}

SPC is a technique that is based on the concept of Shewhart in the process of extensive diversity and is used not only in the manufacturing process but also in the services for the purpose of maintenance of quality. SPC defined as a collection of troubleshooting tools useful in reaching process stability and increase the capacity through reduction of diversity (Montgomery, 2005). The main purpose of the implementation of the SPC is to detect and mitigate sources of variation for the stability of the process. Quality control in food industry scientifically related to technology, the characteristics of sensory, physical, safety, chemical composition and nutritional value. Today, food processing heavily challenged by market-oriented users that require continuous improvement and development of quality food products. Statistically process control is used to describe the changes that can be controlled or not controlled. It exists in all the processes and it is the change of the system and not part of the process because usually arises from some reason. Quality control (QC) is one of the key functions in the manufacturing sector as it relates to the examination of the product before the product is delivered to the customer. Most of the studies conducted are aware that the quality of the production through the production or service has become a necessity in various industries. This is a good method for monitoring a process, and also support the operations of the production opportunities to increase quality and productivity (Lim, 2014).

\section{Application of Statistical Process Control}

In quality management, the use of statistical information that is special way to monitor and control the production process. Statistical information was named statistically process control or SPC. SPC has been developed in the 1930s and became one of the main tools taught in Japanese. Japanese use both to control and improve the quality. All quality experts realized that it is a very important tool for quality control and improvement. SPC is a method to collect and analyze data to solve the problems of quality practical (Rahman, Zain, Alias \& Nopiah (2015). The term statistics mean the conclusions are made in the form of figures or numbers. It involves the data recorded during the manufacturing process and they need to do some calculations. Process refers to the fact that specific production processes and the ability to produce a quality and consistent production. Control means that the monitoring process carried out and his adjustment is necessary so that it will produce the proper way to be implemented (Tybor et al., 2010). As such, the SPC is a method to help production monitor and control a process data collection about the characteristics of the output process, analyze the data, and draw conclusions from data.

Process control in statistics is a basic and proven technique for controlling work processes, especially for the enhancement of quality of work and products. SPC has become a standard method used. SPC techniques function was in helping control the process determine the capability of the process and solve the problem. SPC can be considered as a measure to problem solving that can be used to achieve the stability process as well as increase the capacity reduction that exist. SPC is a tool that can assess and monitor processes in relation to efficiency. It is used to identify defects in quality and can evaluate processes, products or services that do not meet the design specification.

\section{Process Capability}

Review of the efficiency process is an efficient method to test the ability of a process to produce goods which fulfill specifications. Due to the fast growth, the increased usage of QS9000 quality system where the use of study for view ability process is requested (Rohani, \& Yusof \& Mohamad (2009). Findings from the study of the capability need adjustment process applying statistical techniques such as SPC or DoE (Design of experiment). Capability study show that the stability of machine tools for the production process and the capacity assessed with measures necessary to reduce the production of low quality have been carried out using other statistical techniques (Motorcu \& Gullu, 2006). Process capability is the uniqueness of a process that illustrates the limits of random variations in the stable process. A process stable is the process which is controlled at levels statistically that is just random variation exists in the process. Variation of an uncontrolled process may vary at any time, then the estimated variations in the future are not reliable and does not mean. While if the stability of a process does not change then variations in the future can be estimated from the previous process. In other words the capability of the process just means for a stable process only. Mathematically, process capability is defined as the length of the interval that contains $99.7 \%$ natural variations. 
Some statistics that can be used to measure the ability of the process i.e. process capability $(C p)$, process capability index $(C p k)$, process performance $(P p)$ and process performance index (Ppk) (Pyzdek \& Keller, 2014), there are Statistics assume that the population value data is widely distributed normally. Diversity can be expressed as either short term or long term. $\mathrm{Cp}$ and Cpk is based on short term diversity and $\mathrm{Pp}$ and $\mathrm{Ppk}$ is based on the total diversity. In addition, the relationship between the process of natural variations and design specifications are often measured by a measure called the process capability indices (Evans, 1991). From the table 1, its describes the evaluation of measurement in process capability index that are applied as a guide and reference by enterprises in an improving and enhancing the quality.Most manufacturers use $\mathrm{Cp}$ to monitor the quality of operators, and it is also used in the contract of purchase. $\mathrm{Cp}$ formula is as follows:

$$
\mathrm{C} p=\frac{\text { Specification width }}{\text { Process width }}=\frac{\mathrm{USL}-\mathrm{LSL}}{6 \sigma}
$$

From the formula above, the process capability index is described as follows:

Table 1 Capability index and estimates process

\begin{tabular}{|l|l|}
\hline Capability index & Estimates in the process \\
\hline $\mathrm{CPK}=\mathrm{CP}$ & Proses located exactly at the center of the specification limit \\
\hline $\mathrm{CP}<1$ & Process is not adequate \\
\hline $1 \leq \mathrm{CPK}<1.33$ & Process is adequate \\
\hline $\mathrm{CP} \geq 1.33$ & Proses is satisfactory enough \\
\hline $\mathrm{CP} \geq 1.66$ & Proses is very satisfactory \\
\hline $\mathrm{CPK} \neq \mathrm{CPK}$ & Proses is not enough, a new process parameter must be selected \\
\hline
\end{tabular}

Source: Topic of capability index

With larger standard deviation means that natural change is greater. When the natural change is greater than the tolerance spread, $\mathrm{Cp}$ will be less than $1.0(\mathrm{Cp}<1)$. When the natural change is equal to the tolerance spread, $\mathrm{Cp}$ will be $1.0(1 \leq \mathrm{Cp}<1.33)$. If change naturally is smaller than the tolerance spread, means quality is very good in this situation, which means the value of $\mathrm{Cp}$ is greater than $1.33(\mathrm{Cp} \geq 1.33)$ (Kane, 1986).

\subsection{PREAMBLE TO LITERATURE REVIEW}

Data from some source of literature describes the implementation of SPC especially to the food industry is very slow in comparison to other industries such as manufacturing, medical, engineering, chemical and others (Grigg, 1998; Lim, Garza-Reyes \& Arshed, 2015; Lim \& Antony, 2013). The beginning of the preamble refers to the study of literature relating to the implementation of the SPC first with clearly defined scientifically factors and management activities such as involvement or commitment to the management, operating training products by SPC, maneuverability staff in the decision making process and the issue of worker safety (Gordon, Philpot, Bounds \& Long, 1994). In 2003, a total of 10 key ingredients for the success of SPC for manufacturing and services used by Antony and Taner (2003). In turn, the success of the implementation of the SPC also depends on internal and external factors depending on the organisation (Grigg, 1998). Internal factors include for example in terms of Technical or quality Manager, quality systems, management commitment and training, while external factors is in terms of network and customer relationships, support of customer and competitive pressures from suppliers. Even so, there are a few literature combining several literature prior to the review of several aspects such as soft aspect related to the improvement of customer satisfaction and hard aspect to quality example cost of process and performance of the company (Rohani, Yusof \& Mohamad, 2009). Therefore, in summary factors measure under review refers to 3 main factors which managerial factors $(M a F)$, human development factor $(H D F)$ and operational technical factors $(O T F)$. All three of these factors was adopted based on the study by Antony and Taner (2003).

\section{Classifying the Literature}

The statistical process control reviewed focuses on papers published in journal and excludes paper published on the academic journals and conference proceedings. The list of articles was derived from a Google Scholars expanded search spanning the time period from 2007 through 2016. However the previous literature review focusing on the development of the SPC in the food industry for the period 1980 to 2012 but the study focused on the development of SPC through motivations, benefits, challenges and limitations (Lim, 2014). This literature review will emphasize the aspect of SPC knowledge, practices and relationships among food industry players. As such, the study will evaluate the use of SPC for all three factors $(M a F, H D F$ and $O T F)$ and to identify the awareness of SPC application among small and medium enterprises (SMES) of food industry Malaysia. 


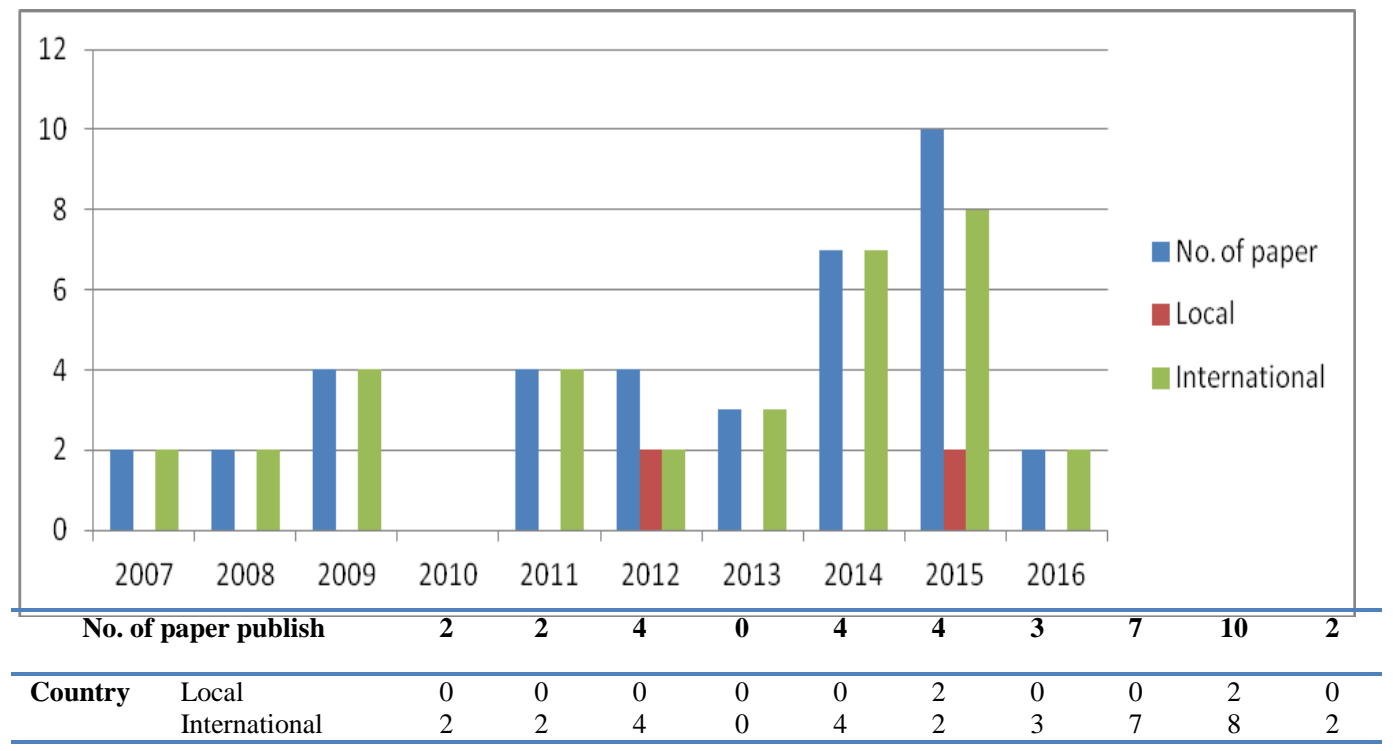

Figure 2 Number of papers found and research location by year up to 2016

From the figures 2 shows the number of papers found and research location by year up to 2016 which is a total of 38 papers from conference proceedings and publishing journal articles that have been published for the past 10 years i.e. 2007-2016 in Malaysia and overseas. Review of this paper shows the total publishing implementation of SPC in Malaysia are less and not given extensive emphasis primarily on the food industry especially to SMEs.

\section{Descriptors used to Classify Article}

The article in SPC implementation especially in food industry is proposed with reference to the 3 main factors the success of SPC described described from the table 2, list of the factors a review article on the implementation of the SPC towards process efficiency. After all, the framework was developed by the previous literature review on the successful use of SPC. The first step in the development of appropriate article selection is to determine pattern or factor suitable for measured to a successful use of the SPC. 3 the range of areas important to classification article literature is focusing: managerial $(M a)$ factor; human development $(H u D)$ factor; and operational $(O p)$ factor. The table below describes the factors survey over articles on the use of the SPC in the food industry.

Table 2 The list of factors a review article on the implementation of the SPC towards process efficiency

\begin{tabular}{ll}
\hline Factor of review & Description \\
\hline Managerial $(\mathbf{M a})$ & $M a$ is relating to management or managers \\
& especially to improved company competitiveness. \\
& This factor includes management commitment, \\
& teamwork, training education for SPC, Awareness \\
& and willing to change, use of pilot study, reward \& \\
& recognition, resources, etc.
\end{tabular}
recognition, resources, etc.

\section{Human \\ Development (HuD)}

$H u D$ is defined as the process of enlarging people's freedom and opportunities to improved customer satisfaction, increase productivity and increase knowledge and awareness in statistics or process. This factor includes resistance to change, conflict between the operator \& computer, cultural change,

\section{Sources}

Pilot study for Indian tea packaging company:

Bharatendra, K. R.(2008);

Organizations integrate continuous improvement:

Bradley,S S., Anne E. Wilcock, V. K.(2009);

Companies had deployed an improvement project systematically: Hsiang, C. H. \& Ming, H. S.;

Process Measurement Capabilities MakingThe Instant Noodles: Enny, A.(2011);

Provides a consolidation the existing knowledge on the SPC implementation: Sarina, A.H.L., Jiju, A., \& Saja, A.(2014); Sarina, A.H.L., \& Jiju, A.(2014); Case study at Kiran Machine Tool Jalgaon. (M.s.): Shri, B., \& Nimbaji, S.(2015);

Reviews the literature related to the CFS's for quality management: Nizam, S. \& Hayati, H.A.T (2015); Towards a Conceptual Roadmap: Sarina,A.H.L, Jiju, A., Jose, A.G.R, \& Norin, A.(2015)

The value of process capability/sigma value to conduct quality control: Enny, A.(2011);

Process capability assessment provides the process should be improved: Milorad, K., \& Milan, A. (2014); 
use of computer \& software package, job security issues, show potential of process capability, etc.

Operational $(\boldsymbol{O p}) \quad O p$ is relating to the routine functioning and activities of a business or organization to improved process understanding and also reduced process variability. This factor include SPC tools, process prioritisation \& definition, corrective action procedure, selection of appropriate quality characteristic (process variable), measurement system, statistical knowledge, etc.
Quality tools by the Saudi food industry: Naser, A. A (2007);

Food industry in UK take advantage of operational improvement initiatives: Rakesh, J (2009);

Sales have increased in the last fiscal year, and companies use Six Sigma and HACCP: Bradley,S S., Anne E. Wilcock, V. K.; Hsiang (2009);

Manufacturing processes in the food industry to reduce quality cost: Hsiang, C. H. \& Ming, H. S.(2011);

Adoption of Management Systems Standards \& Best Practices in Malaysia: Mohd Azman, I., Nor Faridah ,A A., \& Salliza, Z.(2012);

food processing SMEs to improve operational efficiency and reduce costs:.Manoj, D. \& Dirk, V. G. (2014);

Companies show overweight packaging process compared to underfilling packaging: Ilija, D.,Nada, S.,Nikola, T., \& Andreja, R (2014);

Continuous Quality Improvement: Pavol, G.(2015);

Process Capabilities to Reduce Cost: Shri, B., \& Nimbaji, S.(2015);

Basic quality tools with higher utilization: Luis, F., Vanda, L. \& Manuela, S. (2015);

Quality improvement effort to achieve quality management system: Ignatio, M., \& Charles, M. (2016);

\subsection{DISCUSSION}

This study shows the importance of the use of the SPC in the food industry, especially the SMEs in Malaysia. SMEs are an integral part of the business sector in Malaysia, where this sector is also the agribusiness that provides big returns to the country. Therefore, emphasis to the aspects of quality and management is important for the company to manage the right way and controlled in order to become an approach effectively integrates the progress of quality. There are two reasons why SPC should be implemented in SMEs. The first is because the request to supply quality products by large companies, both are the needs of SMEs to be more proactive and able to compete in quality for creating a competitive business environment (Rahman et al., 2015). Generally, the lack of product quality of SMEs will affect the ability to market and competitive company. In Malaysia, the constraints of the SMES to implement quality is due to cost, lack of knowledge, expertise, employee resistance to change and difficulties in releasing employees for training (Rahman, Zain, Saibani, Rahman \& Nopiah, 2010). The implementation of the SPC is a complex activity which in turn involves a change in work culture. This studies found SPC very useful to improve quality process because the company is able to detect major abnormalities in the process, timeliness, checking critical parameter, reduce variation and maintain the stability of the process. As a result, the company managed to reduce customer complaints, increase profitability and productivity improvement.

\subsection{CONCLUSION}

The importance of the study was in the form of theoretical and practical. In terms of practical SMEs can use SPC in improving the efficiency of production processes and performance. In addition, SMEs can overcome the existence of quality problems such as rework, customer complaints and re-examination involving waste and time and high costs. While in terms of theory on the other hand, the use of tools-tools in the SPC techniques can prove that interest in the practice of total quality management (TQM) and ISO boost competition more competitive. While between contributions that could be obtained from this study are as follows:

i. The proposed strategy can be used by management to improve the performance of a process based on statistically process control.

ii. The study proposed a new strategy that is more practical for the management of data quality.

iii. Study on the solution for adding functionality that is able to formulate quality problems related to employee, material, machine or method for analyzing processes, find the cause of the problem, describes the critical problems and preventing recurring problems from happening.

\section{References}

Ab Rahman, M. N., Zain, R. M., Saibani, N., Rahman, S. A., \& Nopiah, Z. M. (2010). Halangan Pelaksanaan SPC: Satu Pandangan Praktikal Daripada Syarikat Pengusaha Kecil Dan Sederhana. Journal of Quality Measurement and Analysis JQMA, 6(2), 1-17. Abdullah, N., \& Rosli, N. F. (2015). An Evaluation on Determinants ff SMEs Performance in Malaysia. 
Antony, J., \& Taner, T. (2003). A Conceptual Framework For The Effective Implementation Of Statistical Process Control. Business Process Management Journal, $9(4), 473-489$.

Baharom, H. (2011). Kamus Dewan Edisi J. Kamaruzzaman, MHWH Wan, AZ Zinatul, Keempat. Kuala Lumpur: Dewan Bahasa dan Pustaka. ZAH Mohd and RMA Mohd.

Evans, J. (1991). Statistical Process Control for Quality Improvement: A Training Guide to Learning SPC: Pearson Education.

Grigg, N. P. (1998). Statistical Process Control In UK Food Production: An Overview. International Journal of Quality \& Reliability Management, 15(2), 223-238.

Hubbard, M. R. (2012). Statistical Quality Control For The Food Industry: Springer Science \& Business Media.

Jafri Mohd Rohani, S. r., \& Mohd Yusof, I. M. (2009). Statistical Process Control Success Factors And Performance: An Exploratory Analysis. 1-28.

Juran, J., \& Godfrey, A. B. (1999). Quality handbook. Republished McGraw-Hill.

Jurgen Popp, V. V. T., Arthur Chiou, Stefan Heinemann (Ed.). (2012). Part One:Process Control and Quality Assurance: 2012.

Kane, V. E. (1986). Process Capability Indices. Journal of Quality Technology, 18(1).

Lim S. and Antony J. (2013). Statistical Process Control Implementation In The Food Industry: A Systematic Review And Implications For Future Research. Proceedings of the 11th International Conference on Manufacturing Research (ICMR2013), Cranfield University, UK, 19th - 20th September 2013, 593598.

Michael E. Gordon, J. W. P., Gregory M. Bounds \& W.Steven Long. (1994). Factors Associated With The Success Of The Implementation Of Statistical Process Control. 5(1), 101-121.

Mohd Nizam Ab Rahman, R. M. Z., Afis Mohd Alias \& Zulkifli Mohd Nopiah. (2015). Statistical Process Control: Best Practices In Small And Medium Enterprises. Maejo International Journal of Science and Technology, 9(02), 193-208.

Montgomery, D. C. (2005). Introduction to Statistical Quality Control, 5th edition

Phyanthamilkumaran, S. Z., Yudi Fernando. (2015). The Role of Cultural Change in the Relationship between Critical Factors with the Success of Statistical Process Control (SPC) Projects. Research Gate.

Pyzdek, T., \& Keller, P. A. (2014). The Six Sigma Handbook: McGraw-Hill Education.

Rohani, J. M., Yusof, S. M., \& Mohamad, I. (2009). The Relationship Between Statistical Process Control Critical Success Factors And Performance: A Structural Equation Modeling Approach. Paper presented at the 2009 IEEE International Conference on Industrial Engineering and Engineering Management.

Sarina Abdul Halim Lim, J. A. S. A. (2014b). Statistical Process Control (SPC) in the Food Industry- A Systematic Review and Future Research Agenda.Unpublished Manuscript.

Sarina Abdul Halim Lim, J. A., Jose Arturo Garza-Reyes and Norin Arshed. (2015). Towards a Conceptual Roadmap for Statistical Process Control Implementation in the Food Industry. Trends in Food Sciences \& Technology, xx, 1-13.

Thareja, P., Sharma, D., \& Mahapatra, P. (2011). Total Quality Management-A Developmental Perspective. Journal of Production Research \& Management, 1(1), 3452.

Tybor, P. T., Hurst, W., Reynolds, A., \& Schuler, G. (2010). Quality Control: A Model Program For The Food Industry. Bulletin-Cooperative Extension Service. 